\title{
Multidisciplinary management of difficult-to-treat drug resistant tuberculosis: a review of cases presented to the national consilium in Uganda
}

Joseph Baruch Baluku ${ }^{1,2^{*}}$, Richard Katuramu ${ }^{3}$, Joshua Naloka ${ }^{4}$, Enock Kizito ${ }^{5}$, Martin Nabwana ${ }^{6}$ and Felix Bongomin ${ }^{7}$

\begin{abstract}
Background: Patients with drug resistant tuberculosis (DR-TB) with comorbidities and drug toxicities are difficult to treat. Guidelines recommend such patients to be managed in consultation with a multidisciplinary team of experts (the "TB consilium") to optimise treatment regimens. We describe characteristics and treatment outcomes of DR-TB cases presented to the national DR-TB consilium in Uganda between 2013 and 2019.

Methods: We performed a secondary analysis of data from a nation-wide retrospective cohort of DR-TB patients with poor prognostic indicators in Uganda. Patients had a treatment outcome documented between 2013 and 2019. Characteristics and treatment outcomes were compared between cases reviewed by the consilium with those that were not reviewed.

Results: Of 1,122 DR-TB cases, 189 (16.8\%) cases from 16 treatment sites were reviewed by the consilium, of whom $86(45.5 \%)$ were reviewed more than once. The most frequent inquiries $(N=308)$ from DR-TB treatment sites were construction of a treatment regimen (38.6\%) and management of side effects (24.0\%) while the most frequent consilium recommendations $(N=408)$ were a DR-TB regimen (21.7\%) and "observation while on current regimen" $(16.6 \%)$. Among the cases reviewed, 152 (80.4\%) were from facilities other than the national referral hospital, 113 (61.1\%) were aged $\geq 35$ years, 72 (40.9\%) were unemployed, and 26 (31.0\%) had defaulted antiretroviral therapy. Additionally, 141 (90.4\%) had hepatic injury, 55 (91.7\%) had bilateral hearing loss, 20 (4.8\%) had psychiatric symptoms and 14 (17.7\%) had abnormal baseline systolic blood pressure. Resistance to second-line drugs (SLDs) was observed among $9(4.8 \%)$ cases while $13(6.9 \%)$ cases had previous exposure to SLDs. Bedaquiline (13.2\%, $n=25)$, clofazimine $(28.6 \%$, $n=54)$, high-dose isoniazid $(22.8 \%, n=43)$ and linezolid $(6.7 \%, n=13)$ were more frequently prescribed among cases reviewed by the consilium than those not reviewed. Treatment success was observed among 126 (66.7\%) cases reviewed.
\end{abstract}

Conclusion: Cases reviewed by the consilium had several comorbidities, drug toxicities and a low treatment success rate. Consilia are important "gatekeepers" for new and repurposed drugs. There is need to build capacity of lower health facilities to construct DR-TB regimens and manage adverse effects.

\footnotetext{
*Correspondence: bbjoe18@gmail.com

1 Division of Pulmonology, Kiruddu National Referral Hospital, Kampala,

Uganda

Full list of author information is available at the end of the article
}

(C) The Author(s) 2021. Open Access This article is licensed under a Creative Commons Attribution 4.0 International License, which permits use, sharing, adaptation, distribution and reproduction in any medium or format, as long as you give appropriate credit to the original author(s) and the source, provide a link to the Creative Commons licence, and indicate if changes were made. The images or other third party material in this article are included in the article's Creative Commons licence, unless indicated otherwise in a credit line to the material. If material is not included in the article's Creative Commons licence and your intended use is not permitted by statutory regulation or exceeds the permitted use, you will need to obtain permission directly from the copyright holder. To view a copy of this licence, visit http://creativecommons.org/licenses/by/4.0/. The Creative Commons Public Domain Dedication waiver (http://creativeco mmons.org/publicdomain/zero/1.0/) applies to the data made available in this article, unless otherwise stated in a credit line to the data. 
Keywords: Consilium, Difficult to treat, Multidisciplinary teams, MDR TB, Uganda, Outcomes

\section{Background}

Drug resistant tuberculosis (DR-TB) is a threat to tuberculosis (TB) control with $\sim 500,000$ cases of rifampicin resistance (RR) reported in 2019 [1]. In some parts of sub-Saharan Africa (SSA), the prevalence of DR-TB has been reported to be $20 \%$ among new TB patients, $53 \%$ among previously treated $\mathrm{TB}$ patients and the rate of decline of multi-drug resistant TB (MDR-TB) in SSA is dismal $[2,3]$. The MDR-TB treatment success rate is low and only $57 \%$ of patients on conventional treatment regimens have a successful outcome [4].

Comorbid conditions such as human immunodeficiency virus (HIV) infection, diabetes mellitus, cancer, alcohol and cigarette use, in addition to cavitary TB disease, resistance to second-line drugs (SLDs), preand extensively drug resistant TB (XDR-TB) and drug adverse effects complicate management of DR-TB and contribute to the poor outcomes [5-10]. Primary health workers in low-income settings find patients with these conditions to be difficult-to-treat and expert opinion is often needed. Such patients may require substitution of drugs in the standard regimen, dose adjustment, discontinuation of a single agent or inclusion of less efficacious agents in the treatment regimen [10-12].

A survey of TB and MDR/XDR-TB management in European countries revealed that there was significant discordance between guidelines and the practice of health care workers in regimen selection (characterised by fewer than 4 drugs in the regimen, incorrect drug choice, inadequate dose prescription, short treatment duration and inadequate management of adverse events of treatment), anti-retroviral therapy (ART) prescription in the HIV co-infected and documentation of treatment outcomes [13]. Similar discordance between guidelines and practice in DR-TB management has been reported in SSA [14]. The World Health Organization (WHO) recommends the formation of national clinical review committees (TB consilia) consisting of multidisciplinary teams that include representation from health care professionals that have expertise in surgery, paediatrics, adult medicine, radiology, psychology, nutrition, and nursing among others [15]. The clinical review committee is a formal system of consultation and provides consensus on evidence-based treatment approaches for difficult-to-treat patients [16]. With the advent of new anti-TB drugs, the consilia are thought to be key as "gate keepers" to guide the judicious use of these agents to protect them from resistance [17]. Primary health care workers can access the input of the consilia through a phone, post office, email, web or physical meetings [17].

In Uganda, such a consilium (also known as a DR-TB review panel) is expected to hold monthly in-person meetings to discuss complex cases referred from DR-TB treatment sites across the country [18]. Despite the utility of these consilia, there has been no nationwide evaluation of their impact on DR-TB treatment outcomes of difficult-to-treat patients in low-income settings. The reports available $[16,19]$ are mostly from high-income countries with low TB/HIV burden, yet formulation and functionality of consilia in resource-limited settings pose time and human resource constraints in an already overstretched health system.

In this study, we describe characteristics and treatment outcomes of DR-TB cases presented to the national DR-TB consilium in Uganda drawn from a large nationwide cohort [20] of patients with poor prognostic indicators, of whom $59 \%$ were HIV co-infected.

\section{Methods}

\section{Study population and design}

We conducted secondary analysis of data from a nationwide retrospective cohort [20] of DR-TB patients with poor prognostic indicators who had laboratory confirmed DR-TB and a treatment outcome documented between January 2013 and December 2019. We extracted data for patients reviewed by the national DR-TB consilium during the same period. Because we sought to compare characteristics of cases reviewed with those that were not reviewed, no cases were excluded in the current analysis.

\section{The DR-TB consilium in Uganda}

The national DR-TB consilium in Uganda is hosted at Mulago National Referral Hospital (MNRH) tuberculosis unit. MNRH is in Kampala, the capital city of Uganda and the TB unit serves as the centre of excellence for susceptible TB and DR-TB care to which all other units of the hospital and peripheral facilities refer patients for diagnosis and TB treatment. There are 16 other DR-TB treatment centres in the country that comprise of 13 rural regional referral hospitals and three general district hospitals. At the time of conducting the study, the national DR-TB consilium in Uganda comprised of two pulmonologists, two internal medicine physicians, a paediatric TB specialist, two audiologists, a laboratory technologist from the national tuberculosis reference laboratory, social worker, the national DR-TB coordinator, 
a radiology resident, three TB community linkage facilitators, adult and paediatric TB nurses and the National TB and Leprosy Program manager. The consilium held in-person meetings every 2 weeks to discuss difficultto-treat cases. The difficult-to-treat cases were referred from all DR-TB treatment centres (including MNRH). All DR-TB treatment centers in Uganda were recommended to have local expert panels to review all patients initiating DR-TB treatment but the composition of local panels depended on the expertise available at each center.

Case summaries were sent by email to the coordinator of the meetings of the national consilium from the DR-TB treatment centers. These were presented to the consilium by a medical officer. The case summary typically had the patient's medical history, most relevant clinical examination findings, and laboratory and imaging investigations done. The summary highlighted the clinical inquiry for which the treatment site is consulting about. After deliberation, an action plan was drawn and was communicated by phone or e-mail by the meeting secretary to the referring treatment site which documented the consilium recommendations in the patient chart and executed the proposed management plan. In January 2019, the consilium started using video tele-conferencing (Project ECHO (University of New Mexico)) with the DR-TB treatment sites in which the individual site representative presented the case summary of the difficult-to-treat case to a physical meeting of the consilium members. The consilium has been in existence since 2013 .

\section{Study measurements}

In the primary study, data were abstracted from participant charts using a data abstraction form. In the current analysis, demographic data (level of DR-TB treatment facility, age, sex, employment status, and marital status), clinical characteristics (alcohol and cigarette use, HIV status, HIV treatment details, TB resistance profiles, DR-TB treatment details, liver function tests, haemoglobin levels, and audiograms), treatment outcomes (cured, treatment completion, loss-to-follow-up, and death) and consilium review details were abstracted. For the consilium review, the number of times the case was reviewed was determined. The total number of inquiries and recommendations of the panel were also enumerated. Full details of the primary study measurements and programmatic management of DR-TB in Uganda are provided elsewhere $[20,21]$. Treatment outcomes were defined according to WHO definitions [22].

\section{Statistical analysis}

Data were analysed with Stata 15.0 (STATA, College Station, Texas, USA). We used descriptive statistics and reported frequencies and proportions alongside the $95 \%$ confidence intervals (CI). Characteristics and outcomes were compared between cases reviewed by the consilium and those not reviewed.

\section{Results}

Data on 1,112 DR-TB cases were extracted from the primary data set. Of these, 189 (16.8\%) were reviewed by the national DR-TB consilium while 923 (83.2\%) were not reviewed.

\section{Characteristics of patients reviewed by the national DR-TB consilium in Uganda}

Among those reviewed, 86 (45.5\%) were reviewed more than once, 172 (91.0\%) had RR/MDR-TB, 10 (5.3\%) had pre-XDR-TB, 3 (1.6\%) had XDR-TB, 4 (2.1\%) had polyresistant TB and 102 (54.0\%) were HIV co-infected. More characteristics are shown in Tables 1 and 2.

\section{Comparison of consilium-reviewed and non-reviewed cases}

As shown in Tables 1 and 2, among the cases reviewed, $152(80.4 \%)$ were from facilities other than the national referral hospital, $113(62.4 \%)$ were from rural areas, 113 $(61.1 \%)$ were aged $\geq 35$ years, $72(40.9 \%)$ were unemployed, and 26 (31.0\%) had defaulted antiretroviral therapy. Additionally, 141 (90.4\%) had hepatic injury, 55 (91.7\%) had bilateral hearing loss, 20 (4.8\%) had psychiatric symptoms and 14 (17.7\%) had abnormal systolic blood pressure. Resistance to second-line drugs (SLDs) was observed among $9(4.8 \%)$ cases while $13(6.9 \%)$ cases had previous exposure to SLDs. Bedaquiline $(13.2 \%, \mathrm{n}=25)$, clofazimine $(28.6 \%, \mathrm{n}=54)$, high-dose isoniazid (22.8\%, $\mathrm{n}=43)$ and linezolid $(6.7 \%, \mathrm{n}=13)$ were more frequently prescribed among cases reviewed by the consilium than those not reviewed.

\section{Treatment outcomes of cases reviewed by the national DR-TB consilium}

Treatment success was observed among 126 (66.7\%) cases reviewed by the consilium. In comparison, treatment success was observed among 680 (72.9\%) cases that were not reviewed by the consilium. Treatment loss-tofollow-up was observed among 18 (9.5\%) cases reviewed while treatment failure and death occurred among 9 (4.8\%) and 36 (19.0\%) cases reviewed respectively.

\section{Clinical inquiries from DR-TB sites and recommendations of the consilium}

The most frequent inquiries $(\mathrm{N}=308)$ from $\mathrm{DR}-\mathrm{TB}$ sites were construction of a treatment regimen $(38.6 \%)$, management of side effects $(24.0 \%)$ and determination of treatment duration (21.8\%). The most frequent recommendations $(\mathrm{N}=408)$ were a DR-TB regimen $(21.7 \%)$, 
Table 1 A comparison of sociodemographic characteristics of DR-TB cases reviewed by the national DR-TB consilium with those not reviewed

\begin{tabular}{|c|c|c|c|c|}
\hline \multirow{2}{*}{$\begin{array}{l}\text { Socio- } \\
\text { demographic } \\
\text { characteristic }\end{array}$} & \multicolumn{4}{|c|}{ Review status } \\
\hline & $\begin{array}{l}\text { Not } \\
\text { reviewed } \\
n=933\end{array}$ & $95 \% \mathrm{Cl}$ & $\begin{array}{l}\text { Reviewed } \\
n=189\end{array}$ & $95 \% \mathrm{Cl}$ \\
\hline
\end{tabular}

Level of treatment site

\begin{tabular}{|c|c|c|c|c|}
\hline $\begin{array}{l}\text { Mulago National } \\
\text { Referral Hos- } \\
\text { pital }\end{array}$ & $284(30.4)$ & $27.6,33.5$ & 37 (19.6) & $14.5,25.9$ \\
\hline $\begin{array}{l}\text { Regional refer- } \\
\text { ral hospital }\end{array}$ & $533(57.1)$ & $53.9,60.3$ & $120(63.5)$ & $56.3,70.1$ \\
\hline District hospital & $116(12.4)$ & $10.5,14.7$ & $32(16.9)$ & $12.2,23.0$ \\
\hline \multicolumn{5}{|c|}{ Residence, $n=1076$} \\
\hline Rural & $583(65.1)$ & $62.0,68.2$ & $113(62.4)$ & $55.1,69.2$ \\
\hline Urban & $312(34.9)$ & $31.8,38.0$ & $68(37.6)$ & $30.8,44.9$ \\
\hline \multicolumn{5}{|l|}{ Age, $n=1080$} \\
\hline$<15$ & $22(2.5)$ & $1.6,3.7$ & $5(2.7)$ & $1.1,6.4$ \\
\hline $15-34$ & $387(43.2)$ & $40.0,46.5$ & $67(36.2)$ & $29.6,43.4$ \\
\hline $35-60$ & $449(50.2)$ & $46.9,53.4$ & $94(50.8)$ & $43.6,58.0$ \\
\hline$>60$ & $37(4.1)$ & $3.0,5.7$ & $19(10.3)$ & $6.6,15.6$ \\
\hline \multicolumn{5}{|l|}{ Sex } \\
\hline Male & $590(63.2)$ & $60.1,66.3$ & $119(63)$ & $55.8,69.6$ \\
\hline Female & $343(36.8)$ & $33.7,39.9$ & $70(37)$ & $30.4,44.2$ \\
\hline \multicolumn{5}{|c|}{ Pregnancy status,$n=413$} \\
\hline Pregnant & $13(3.8)$ & $2.2,6.4$ & $5(7.1)$ & $3.0,16.3$ \\
\hline Breastfeeding & $11(3.2)$ & $1.8,5.7$ & $5(7.1)$ & $3.0,16.3$ \\
\hline None & $319(93)$ & $89.8,95.3$ & $60(85.7)$ & $75.2,92.2$ \\
\hline \multicolumn{5}{|c|}{ Nature of employment, $n=1060$} \\
\hline Unemployed & $280(31.7)$ & $28.7,34.8$ & $72(40.9)$ & $33.8,48.4$ \\
\hline Self employed & $402(45.5)$ & $42.2,48.8$ & $73(41.5)$ & $34.4,48.9$ \\
\hline Employed & $202(22.9)$ & $20.2,25.7$ & $31(17.6)$ & $12.6,24.0$ \\
\hline \multicolumn{5}{|c|}{ Marital Status, $n=1069$} \\
\hline Married & $446(50.6)$ & $47.3,53.9$ & $89(47.3)$ & $40.3,54.5$ \\
\hline Single & $217(24.6)$ & $21.9,27.6$ & $50(26.6)$ & $20.7,33.4$ \\
\hline Divorced & $25(2.8)$ & $1.9,4.2$ & $3(1.6)$ & $0.5,4.9$ \\
\hline Separated & $137(15.6)$ & $13.3,18.1$ & $39(20.7)$ & $15.5,27.2$ \\
\hline Widowed & $56(6.4)$ & $4.9,8.2$ & $7(3.7)$ & $1.8,7.6$ \\
\hline \multicolumn{5}{|c|}{ Alcohol use, $n=816$} \\
\hline Never & $412(62)$ & $58.2,65.6$ & $91(60.3)$ & $52.2,67.8$ \\
\hline Ever used & $253(38)$ & $34.4,41.8$ & $60(39.7)$ & $32.2,47.8$ \\
\hline \multicolumn{5}{|c|}{ Cigarette smoking, $n=816$} \\
\hline Never & $541(81.4)$ & $78.2,84.1$ & $120(79.5)$ & $72.2,85.2$ \\
\hline Ever used & $124(18.6)$ & $15.9,21.8$ & $31(20.5)$ & $14.8,27.8$ \\
\hline
\end{tabular}

${ }^{*}$ Among females, $\mathrm{Cl}$-confidence interval

observation while on current regimen $(16.6 \%)$ and treatment adherence counselling (14.0\%). Notably, the number of inquiries and recommendations were more than the number of cases reviewed because some cases were reviewed more than once and had more than one inquiry or recommendation. Table 3 shows clinical inquiries from DR-TB sites and recommendations from the consilium.

\section{Discussion}

In this study, we evaluated the characteristics and treatment outcomes of DR-TB cases reviewed by the national DR-TB consilium in Uganda, a TB/HIV high-burdened country. We found that DR-TB facilities mostly inquired about construction of DR-TB regimens and management of side effects. The consilium mostly recommended DR-TB treatment regimens and observation of patients while on a given regimen. Patients reviewed by the consilium were more likely to be from facilities other than MNRH, aged $\geq 35$ years, unemployed, defaulted ART, had baseline systolic hypotension, hepatic injury, bilateral hearing loss, psychiatric symptoms, resistance to SLDs and previous exposure to SLDs. Further, reviewed cases were more likely to be prescribed bedaquiline, clofazimine, linezolid and high-dose isoniazid. Treatment success was lower among cases reviewed by the consilium. To our knowledge, this is the first report on cases reviewed by national TB consilia in SSA.

Our results suggest that health workers in peripheral facilities face challenges in constructing regimens for patients with comorbidities and management of adverse drug events. This highlights the need to build the capacity of health workers in these facilities-where most patients were initiated on therapy-to be able to design optimal DR-TB regimens. While there have been efforts to improve health worker skills in DR-TB management in Uganda, there has not been an evaluation of health worker knowledge and practices regarding DR-TB in Uganda [21]. DR-TB knowledge among health workers is consistently low in SSA [24-26]. Similar to our findings, the core clinical questions raised by health workers in Belgium and the United Kingdom (UK) were about the treatment regimen, management of adverse effects, and duration of therapy [16]. In France and the UK, preventive treatment for DR-TB contacts, management of non-tuberculous mycobacterial infection, rifampicin and isoniazid monoresistance, and interpretation of molecular tests were among the clinical questions handled by the consilia, which was not observed in our study [16]. However, from our experience as members of the consilium, these are common clinical queries raised by health workers in Uganda. It is likely that poor documentation of consilium recommendations in the patients' charts explains why they were not enumerated in our study.

Cases presented to the consilium were more likely to have poor DR-TB prognostic indicators that included advanced age, low socioeconomic status (unemployment as a proxy), drug toxicities (hepatic injury, hearing loss, and psychiatric symptoms), poor ART adherence 
Table 2 A comparison of clinical characteristics the DR-TB cases reviewed by the national DR-TB consilium with those not reviewed

\begin{tabular}{|c|c|c|c|c|}
\hline \multirow[t]{2}{*}{ Clinical characteristic } & \multicolumn{4}{|l|}{ Review status } \\
\hline & Not reviewed $n=933$ & $95 \% \mathrm{Cl}$ & Reviewed $n=189$ & $95 \% \mathrm{Cl}$ \\
\hline \multicolumn{5}{|c|}{ Body mass index, $\mathrm{kg} / \mathrm{m}^{2} \mathrm{n}=473$} \\
\hline$<18.5$ & $195(55.9)$ & $50.6,61.0$ & $81(65.3)$ & $56.5,73.2$ \\
\hline $18.5-24.9$ & $142(40.7)$ & $35.6,45.9$ & $39(31.5)$ & $23.8,40.2$ \\
\hline $25.0-29.9$ & $12(3.4)$ & $2.0,6.0$ & $4(3.2)$ & $1.2,8.4$ \\
\hline \multicolumn{5}{|l|}{ History of TB treatment } \\
\hline Yes & $556(59.6)$ & $56.4,62.7$ & $107(56.6)$ & $49.4,63.5$ \\
\hline No & $377(40.4)$ & $37.3,43.6$ & $82(43.4)$ & $36.5,50.6$ \\
\hline \multicolumn{5}{|l|}{ HIV Status } \\
\hline Positive & $564(60.5)$ & $57.3,63.5$ & $102(54)$ & $46.8,61.0$ \\
\hline Negative & $369(39.5)$ & $36.5,42.7$ & $87(46)$ & $39.0,53.2$ \\
\hline \multicolumn{5}{|l|}{ Cotrimoxazole use, $n=603$} \\
\hline Yes & $491(97)$ & $95.1,98.2$ & $96(99)$ & $92.9,99.9$ \\
\hline No & $15(3)$ & $1.8,4.9$ & $1(1)$ & $0.1,7.1$ \\
\hline \multicolumn{5}{|l|}{ ART use, $n=655$} \\
\hline Yes & $521(94)$ & $91.7,95.7$ & $101(100)$ & - \\
\hline No & $33(6)$ & $4.3,8.3$ & $0(0)$ & - \\
\hline \multicolumn{5}{|c|}{ History of ART default, $n=491$} \\
\hline Yes & $60(14.7)$ & $11.6,18.5$ & $26(31)$ & $21.9,41.8$ \\
\hline No & $347(85.3)$ & $81.5,88.4$ & $58(69)$ & $58.2,78.1$ \\
\hline \multicolumn{5}{|l|}{ Diabetes, $n=151$} \\
\hline Yes & $36(33)$ & $24.8,42.5$ & $12(28.6)$ & $16.7,44.4$ \\
\hline No & $73(67)$ & $57.5,75.2$ & $30(71.4)$ & $55.6,83.3$ \\
\hline \multicolumn{5}{|l|}{ Hypertension, $n=479$} \\
\hline Yes & $19(4.6)$ & $2.9,7.0$ & $5(8.1)$ & $3.3,18.2$ \\
\hline No & $398(95.4)$ & $93.0,97.1$ & $57(91.9)$ & $81.8,96.7$ \\
\hline \multicolumn{5}{|c|}{ Systolic blood pressure, $n=479$} \\
\hline$<90$ & $32(7.7)$ & $5.5,10.7$ & $10(16.1)$ & $8.8,28.7$ \\
\hline $90-140$ & $375(89.9)$ & $86.6,92.5$ & $48(77.4)$ & $65.1,86.3$ \\
\hline$>140$ & $10(2.4)$ & $1.3,4.4$ & $4(6.5)$ & $2.4,16.2$ \\
\hline \multicolumn{5}{|c|}{ Diastolic blood pressure, $n=479$} \\
\hline$<60$ & $41(9.8)$ & $7.3,13.1$ & $10(16.1)$ & $8.8,27.7$ \\
\hline $60-90$ & $362(86.8)$ & $83.2,89.7$ & $51(82.3)$ & $70.5,90.0$ \\
\hline$>90$ & $14(3.4)$ & $2.0,5.6$ & $1(1.6)$ & $0.2,11.0$ \\
\hline \multicolumn{5}{|l|}{ Cancer } \\
\hline No & $919(98.5)$ & $97.5,99.1$ & $186(98.4)$ & $95.2,99.5$ \\
\hline Yes & $14(1.5)$ & $0.9,2.5$ & $3(1.6)$ & $0.5,4.8$ \\
\hline \multicolumn{5}{|c|}{ Elevated creatinine ${ }^{\dagger}, n=934$} \\
\hline Yes & $231(29.4)$ & $26.3,32.6$ & $48(32.7)$ & $25.5,40.7$ \\
\hline No & $556(70.6)$ & $67.4,73.7$ & $99(67.3)$ & $59.3,74.5$ \\
\hline \multicolumn{5}{|l|}{ Hepatic injury,$n=928$} \\
\hline Yes & $639(82.8)$ & $79.9,85.3$ & $141(90.4)$ & $84.6,94.1$ \\
\hline No & $133(17.2)$ & $14.7,20.1$ & $15(9.6)$ & $5.9,15.4$ \\
\hline \multicolumn{5}{|c|}{ Hearing impairment, $n=803$} \\
\hline Normal Hearing & $351(54.5)$ & $50.6,58.3$ & $93(58.5)$ & $50.6,65.9$ \\
\hline Low Frequency & $113(17.5)$ & $14.8,20.7$ & $24(15.1)$ & $10.3,21.6$ \\
\hline High Frequency & $180(28)$ & $24.6,31.6$ & $42(26.4)$ & $20.1,33.9$ \\
\hline \multicolumn{5}{|c|}{ Distribution of hearing loss, $n=348$} \\
\hline Bilateral hearing loss & $233(80.9)$ & $75.9,85.1$ & $55(91.7)$ & $81.2,96.6$ \\
\hline
\end{tabular}


Table 2 (continued)

\begin{tabular}{|c|c|c|c|c|}
\hline \multirow[t]{2}{*}{ Clinical characteristic } & \multicolumn{4}{|l|}{ Review status } \\
\hline & Not reviewed $n=933$ & $95 \% \mathrm{Cl}$ & Reviewed $n=189$ & $95 \% \mathrm{Cl}$ \\
\hline Unilateral hearing loss & $55(19.1)$ & $14.9,24.1$ & $5(8.3)$ & $3.4,18.8$ \\
\hline \multicolumn{5}{|c|}{ Grade of hearing loss, $n=314$} \\
\hline Mild & $145(55.3)$ & $49.2,61.3$ & $20(38.5)$ & $26.1,52.6$ \\
\hline Moderate & $65(24.8)$ & $19.9,30.4$ & $18(34.6)$ & $22.8,48.7$ \\
\hline Severe & $34(13)$ & $9.4,17.6$ & $9(17.3)$ & $9.1,30.4$ \\
\hline Profound & $18(6.9)$ & $4.4,10.7$ & $5(9.6)$ & $4.0,21.5$ \\
\hline \multicolumn{5}{|l|}{ Psychiatric symptoms } \\
\hline Yes & $49(5.3)$ & $4.0,6.9$ & $20(10.6)$ & $6.9,15.9$ \\
\hline No & $884(94.7)$ & $93.1,96.0$ & $169(89.4)$ & $84.1,93.1$ \\
\hline \multicolumn{5}{|l|}{ Resistance to SLDs } \\
\hline Yes & $4(0.4)$ & $0.1,1.1$ & $9(4.8)$ & $2.5,8.9$ \\
\hline No & $929(99.6)$ & $98.9,99.8$ & $180(95.2)$ & $91.1,97.5$ \\
\hline \multicolumn{5}{|l|}{ Previous exposure to SLDS } \\
\hline Yes & $17(1.8)$ & $1.1,2.9$ & $13(6.9)$ & $4.0,11.5$ \\
\hline No & $916(98.2)$ & $97.1,98.9$ & $176(93.1)$ & $88.5,96.0$ \\
\hline
\end{tabular}

Table 3 Clinical inquiries from DR-TB treatment sites and recommendations of the consilium

\begin{tabular}{ll}
\hline & Count (\%) \\
\hline Clinical inquiries from DR-TB sites (N=308) & \\
Construction of treatment regimen & $119(38.6)$ \\
Management of adverse effect & $74(24.0)$ \\
Determination treatment duration & $67(21.8)$ \\
Validation of already prescribed regimen & $30(9.7)$ \\
Establishment of DR-TB diagnosis & $17(5.5)$ \\
Unknown & $1(0.3)$ \\
Recommendations of consilium (N=471) & \\
Construction of initial DR-TB regimen & $102(21.7)$ \\
Observation while on current regimen & $78(16.6)$ \\
Adherence counselling & $66(14.0)$ \\
Dose adjustment & $36(7.6)$ \\
Further diagnostic work up & $35(7.4)$ \\
Further clinical evaluation by specialist & $32(6.8)$ \\
Substitution of single agent in the regimen & $30(6.4)$ \\
Change of regimen (substituting 2 or more agents) & $25(5.3)$ \\
Adjunct medication & $23(4.9)$ \\
Withholding a single agent without substituting it & $15(3.2)$ \\
Withholding all DR-TB treatment for a while & $13(2.8)$ \\
Other recommendation & $16(3.4)$ \\
\hline
\end{tabular}

DR-TB-drug resistant tuberculosis and more extensive resistance profiles. This is expected because consilia predominantly deal with complex clinical scenarios. It is concerning that patients with severe anaemia were not preferentially reviewed by the consilium yet severe anaemia has been associated with a $91 \%$ reduction in the odds of treatment success in this cohort [20]. It is important that the consilium in Uganda prioritises review of patients with anaemia. Similar to our findings, in France, cases were more likely to be presented to the consilium if they had XDR-TB [27]. In the current study, the consilium was more likely to be involved in designing regimens with new DR-TB agents (bedaquiline), repurposed drugs (clofazimine and linezolid) and drugs in short-term treatment regimens (high-dose isoniazid) in tandem with the evolving DR-TB treatment regimens [28]. This demonstrates that the consilium has been acting as a "gatekeeper" for new and repurposed drugs and providing expert advice based on internationally approved guidelines. Other consilia have played a role in the progressive roll out of bedaquiline which was initially provided on compassionate basis before the current recommendation as a core "group A" drug [16, 29].

Treatment outcomes of patients reviewed by the TB consilia elsewhere have not been well described, particularly in SSA. Current reports focus on the performance of the consilia by evaluating the overall treatment outcomes of DR-TB patients in countries with such consilia. D'Ambrosio et al.[16] provide an excellent evaluation of the achievements of the different consilia across Europe 
and Mexico. They report that the treatment success rate in Belarus improved from 37\% in 2010 to $54 \%$ in 2016 after establishment of the consilia. In Belgium they note that most of the DR-TB patients diagnosed since 2011 benefited from the consilium advice and the country reported a $92.3 \%$ treatment success rate for MDR-TB and $100 \%$ for XDR-TB. In Mexico, the treatment success rate achieved between 2010, when the consilium was established, to 2017 was $70 \%$. However, it is unclear what the treatment success rate before establishment of the consilium was. In Portugal, the treatment success was observed in $72 \%$ of DR-TB patients, $23 \%$ of whom were XDR-TB. In Papua New Guinea, the establishment of the tele-based consilium has seen improvement of DR-TB treatment outcomes from 70 to $81 \%$, although it is difficult to attribute these outcomes solely to the establishment of the consilium $[29,30]$. The treatment success rate observed among cases reviewed by the consilium in Uganda is commendable considering the several comorbidities, drug adverse effects and high HIV prevalence in the cases. The treatment success rate among the cases is considerably higher than the global DR-TB success rate of $57 \%$ [1], although it is below the global DR-TB target of $\geq 75 \%$.

Our study has some limitations. The retrospective nature of the study potentially introduces information bias since we used retrospective data which could have missed certain consilium recommendations. This was minimised by reviewing e-mail correspondence with sites and health care providers who were present in the respective consilia sittings. Notwithstanding, the large sample size of the primary nationwide cohort accorded us the ability to make meaningful comparisons between cases reviewed with those that were not reviewed.

In conclusion, our study showed a commendable treatment success rate among DR-TB cases reviewed by the multidisciplinary TB consilium in Uganda. Our results suggest that health workers in peripheral facilities face challenges in constructing regimens for patients with comorbidities and management of adverse drug events. This highlights the need to build the capacity of health workers in these facilities.

\footnotetext{
Abbreviations

TB: Tuberculosis; SSA: Sub-Saharan Africa; DR-TB: Drug resistant tuberculosis; MDR-TB: Multi-drug resistant tuberculosis; XDR-TB: Extensively drug resistant tuberculosis; RR: Rifampicin resistance; WHO: World health organisation; HIV: Human immunodeficiency virus; MNRH: Mulago National Referral Hospital; UK: United Kingdom; SLDs: Second-line drugs; ART: Antiretroviral therapy; WHO: World Health organisation.
}

\section{Acknowledgements}

None.

\section{Authors' contributions}

JBB - conceptualisation, design, data accrual, formal analysis, interpretation of results, drafting manuscript, manuscript revision, approval of final report. RKDesign, interpretation of results, manuscript revision, approval of final report. $\mathrm{JN}$ - conceptualisation, data accrual, interpretation of results, manuscript revision, approval of final report. EK-Interpretation of results, manuscript revision, approval of final report. MN-Formal analysis, interpretation of results, manuscript revision, approval of final report. FB-Design, interpretation of results, manuscript revision, approval of final report. All authors read and approved the final manuscript.

\section{Funding}

Funding for this research was obtained from the East African Public Health Laboratory Networking (EAPHLN) Project, Uganda under the Ministry of Health, which was supported by the World Bank. The funders had no role in study design, data collection and analysis, decision to publish, or preparation of the manuscript.

\section{Availability of data and materials}

The datasets used and/or analysed during the current study available from the corresponding author on reasonable request.

\section{Declarations}

\section{Ethical approval and consent to participate}

The study was approved by the Mulago Hospital Research and Ethics Committee (\#MHREC 1679) which provided waiver of consent since we used deidentified secondary data. Further approval from the Uganda National Council of Science and Technology was obtained. All experiments and handling of data were conducted in accordance to the Declaration of Helsinki.

\section{Consent for publication}

Not applicable.

\section{Competing interests}

The authors declare no conflict of interests.

\section{Author details}

${ }^{1}$ Division of Pulmonology, Kiruddu National Referral Hospital, Kampala, Uganda. ${ }^{2}$ Makerere University Lung Institute, Kampala, Uganda. ${ }^{3}$ Uganda Ministry of Health, Kampala, Uganda. ${ }^{4}$ Mulago National Referral Hospital, Kampala, Uganda. ${ }^{5}$ USAID/Defeat TB, University Research Co LLC, Kampala, Uganda.

${ }^{6}$ Makerere University - Johns Hopkins University Research Collaboration, Kampala, Uganda. ${ }^{7}$ Department of Medical Microbiology and Immunology, Faculty of Medicine, Gulu University, Gulu, Uganda.

Received: 24 March 2021 Accepted: 3 June 2021

Published online: 10 July 2021

\section{References}

1. World Health Organization. Global tuberculosis report 2020. In: Global tuberculosis report 2020. 2020.

2. Musa BM, Adamu AL, Galadanci NA, Zubayr B, Odoh CN, Aliyu MH. Trends in prevalence of multi drug resistant tuberculosis in sub-Saharan Africa: A systematic review and meta-analysis. PLoS ONE [Internet]. 2017 Sep 25 [cited 2019 Apr 21];12(9). Available from: https://www.ncbi.nlm.nih.gov/ pmc/articles/PMC5612652/

3. Otu J, Gehre F, Zingue D, Kudzawu S, Forson A, Mane M, et al. Multidrugresistant tuberculosis (mdr-Tb): an emerging problem in West Africa. BMJ Glob Health. 2017;2(Suppl 2):A32-3.

4. Kibret KT, Moges Y, Memiah P, Biadgilign S. Treatment outcomes for multidrug-resistant tuberculosis under DOTS-Plus: a systematic review and meta-analysis of published studies. Infect Dis Poverty. 2017;6(1):7.

5. Meressa D, Hurtado RM, Andrews JR, Diro E, Abato K, Daniel T, et al. Achieving high treatment success for multidrug-resistant TB in Africa: initiation and scale-up of MDR TB care in Ethiopia-an observational cohort study. Thorax. 2015;70(12):1181-8. 
6. Kliiman K, Altraja A. Predictors of poor treatment outcome in multi- and extensively drug-resistant pulmonary TB. Eur Respir J. 2009;33(5):1085-94.

7. Leveri TH, Lekule I, Mollel E, Lyamuya F, Kilonzo K. Predictors of treatment outcomes among multidrug resistant tuberculosis patients in Tanzania [Internet]. Tuberculosis Research and Treatment. 2019 [cited 2019 Apr 21]. https://www.hindawi.com/journals/trt/2019/3569018/ref/

8. Samuels JP, Sood A, Campbell JR, Ahmad Khan F, Johnston JC. Comorbidities and treatment outcomes in multidrug resistant tuberculosis: a systematic review and meta-analysis. Sci Rep [Internet]. 2018 Mar 21 [cited 2019 Apr 21];8. https://www.ncbi.n/m.nih.gov/pmc/articles/PMC58 62834/

9. Tang S, Tan S, Yao L, Li F, Li L, Guo X, et al. Risk factors for poor treatment outcomes in patients with MDR-TB and XDR-TB in China: retrospective multi-center investigation. PLoS ONE [Internet]. 2013 Dec 5 [cited 2019 Apr 21];8(12). https://www.ncbi.n/m.nih.gov/pmc/articles/PMC3857781/

10. Zhang Y, Wu S, Xia Y, Wang N, Zhou L, Wang J, et al. Adverse events associated with treatment of multidrug-resistant tuberculosis in china: an ambispective cohort study. Med Sci Monit Int Med J Exp Clin Res. 2017; 18(23):2348-56.

11. Chang K-C, Yew W-W, Tam C-M, Leung C-C. WHO Group 5 drugs and difficult multidrug-resistant tuberculosis: a systematic review with cohort analysis and meta-analysis. Antimicrob Agents Chemother. 2013;57(9):4097-104.

12. Winters N, Butler-Laporte G, Menzies D. Efficacy and safety of World Health Organization group 5 drugs for multidrug-resistant tuberculosis treatment. Eur Respir J. 2015;46(5):1461-70.

13. Migliori GB, Sotgiu G, D'Ambrosio L, Centis R, Lange C, Bothamley G, et al. TB and MDR/XDR-TB in European union and European economic area countries: managed or mismanaged? Eur Respir J. 2012;39(3):619-25.

14. Water BJ van de, Silva SG, Bettger JP, Humphreys J, Cunningham CK, Farley JE. Provision of guideline-based care for drug-resistant tuberculosis in South Africa: level of concordance between prescribing practices and guidelines. PLOS ONE. 2018 Nov 5;13(11):e0203749.

15. WHO | Policy Implementation Package for new TB drug introduction [Internet]. WHO. [cited 2019 Apr 17]. https://www.who.int/tb/publicatio ns/implementation-new-tb-drugs/en/

16. D'Ambrosio L, Bothamley G, Caminero Luna JA, Duarte R, Guglielmetti L, Muñoz Torrico M, et al. Team approach to manage difficultto-treat TB cases: experiences in Europe and beyond. Pulmonology. 2018;24(2):132-41.

17. Tiberi S, Pontali E, Tadolini M, D'Ambrosio L, Migliori GB. Challenging MDRTB clinical problems-the case for a new Global TB Consilium supporting the compassionate use of new anti-TB drugs. Int J Infect Dis IJID Off Publ Int Soc Infect Dis. 2019;80S:S68-72.

18. National Tuberculosis and Leprosy Control Program. Uganda National Guidelines for the Programmatic Management of Drug Resistant Tuberculosis [Internet]. Kampala: Ministry of Health; 2011 p. 47. Available from: https://elearning.idi.co.ug/pluginfile.php/5676/mod_page/content/5/ National\%20Drug\%20Resistant\%20-TB\%20Guidelines.pdf

19. Esposito S, D'Ambrosio L, Tadolini M, Schaaf HS, Luna JC, Marais B, et al. ERS/WHO Tuberculosis Consilium assistance with extensively drug-resistant tuberculosis management in a child: case study of compassionate delamanid use. Eur Respir J. 2014;44(3):811-5.

20. Baluku JB, Nakazibwe B, Naloka J, Nabwana M, Mwanja S, Mulwana R, et al. Treatment outcomes of drug resistant tuberculosis patients with multiple poor prognostic indicators in Uganda: A countrywide 5-year retrospective study. J Clin Tuberc Mycobact Dis. 2021;23:100221.

21. Kasozi S, Kirirabwa NS, Kimuli D, Luwaga H, Kizito E, Turyahabwe S, et al. Addressing the drug-resistant tuberculosis challenge through implementing a mixed model of care in Uganda. PLOS ONE. 2020;15(12):e0244451.

22. World Health Organization. Definitions and reporting framework for tuberculosis-2013 revision. World Health Organization; 2013. Report No.: 9241505346.

23. Eller LA, Eller MA, Ouma B, Kataaha P, Kyabaggu D, Tumusiime R, et al. Reference Intervals in Healthy Adult Ugandan Blood Donors and Their Impact on Conducting International Vaccine Trials. PLOS ONE. 2008;3(12):e3919.

24. Malangu N, Adebanjo OD. Knowledge and practices about multidrugresistant tuberculosis amongst healthcare workers in Maseru. Afr J Prim Health Care Fam Med [Internet]. 2015 Mar 27 [cited 2021 Mar 18];7(1). https://www.ncbi.nlm.nih.gov/pmc/articles/PMC4564896/

25. Alene KA, Adane AA, Yifiru S, Bitew BD, Adane A, Koye DN. Knowledge and practice of health workers about control and prevention of multidrug-resistant tuberculosis in referral hospitals, Ethiopia: a cross-sectional study. BMJ Open. 2019;9(2):e022948.

26. Isara A, Akpodiete A. Concerns about the knowledge and attitude of multidrug-resistant tuberculosis among health care workers and patients in Delta State. Nigeria Niger J Clin Pract. 2015;18(5):664-9.

27. Guglielmetti L, Jaffré J, Bernard C, Brossier F, El Helali N, Chadelat K, et al. Multidisciplinary advisory teams to manage multidrug-resistant tuberculosis: the example of the French Consilium. Int J Tuberc Lung Dis. 2019;23(10):1050-4

28. Pontali E, Raviglione MC, Migliori GB. Regimens to treat multidrug-resistant tuberculosis: past, present and future perspectives. Eur Respir Rev [Internet]. 2019 Jun 30 [cited 2021 Mar 19];28(152). https://err.ersjournals. com/content/28/152/190035

29. Huang GKL, Pawape G, Taune M, Hiasihri S, Ustero P, O'Brien DP, et al. Telemedicine in Resource-Limited Settings to Optimize Care for MultidrugResistant Tuberculosis. Front Public Health [Internet]. 2019 [cited 2021 Mar 19];7. Available from: https://www.frontiersin.org/articles/https://doi. org/10.3389/fpubh.2019.00222/full

30. Morris L, Hiasihri S, Chan G, Honjepari A, Tugo O, Taune M, et al. The emergency response to multidrug-resistant tuberculosis in Daru, Western Province, Papua New Guinea, 2014-2017. Public Health Action. 2019;9(Suppl 1):S4-11.

\section{Publisher's Note}

Springer Nature remains neutral with regard to jurisdictional claims in published maps and institutional affiliations.
Ready to submit your research? Choose BMC and benefit from:

- fast, convenient online submission

- thorough peer review by experienced researchers in your field

- rapid publication on acceptance

- support for research data, including large and complex data types

- gold Open Access which fosters wider collaboration and increased citations

- maximum visibility for your research: over 100M website views per year

At BMC, research is always in progress.

Learn more biomedcentral.com/submissions 